\title{
National Health Insurance Scheme of Ejisu-Juaben and Matters Arising
}

\author{
Samuel Adu-Gyamfi ${ }^{1}$, Edward Brenya ${ }^{1}$, \& Aikins Amoah ${ }^{1}$ \\ ${ }^{1}$ Department of History and Political Studies, Kwame Nkrumah University of Science and Technology, Ghana \\ Correspondence: Samuel Adu-Gyamfi, Department of History and Political Studies, Kwame Nkrumah University of \\ Science and Technology, Ghana.
}

Received: June 11, 2015

Accepted: June 25, 2015

Available online: July 22, 2015

doi:10.11114/ijsss.v3i5.962

URL: http://dx.doi.org/10.11114/ijsss.v3i5.962

\begin{abstract}
The Ejisu-Juaben Health Insurance Scheme (EJHIS), a municipal health insurance scheme in the Asante Region, provides insurance cards to subscribers in the municipality to access affordable health care from accredited health facilities. The study was carried out to find out the extent to which health care is accessible and affordable to the people and to determine the sustainability of the scheme. Ten communities in the municipality were purposively selected. These communities cut across the entire municipality; these include both urban and rural settlements. The study adopted the descriptive survey design using the case study approach focusing on accessibility, affordability and sustainability of the health insurance scheme. In all 120 participants were selected for the study which includes managers, health service providers and subscribers comprising opinion leaders, community leaders and community members. Data was collected using semi-structured interview and interview guide. Responses were coded and analyzed. Findings showed that the government and the administrators at Ejisu-Juaben are committed to the implementation of health insurance policy and provide improved health care in the municipality. The study recommends a strong collaboration based on understanding among the scheme management, the health service providers and subscribers in Order to achieve a successful, affordable, accessible and sustainable health care. Scheme managers are urged to make the insurance more attractive, and create enhanced communication channels to promote transparency in their operations.
\end{abstract}

Keywords: National Health Insurance Scheme, Subscribers, Scheme Managers, Ejisu-Juaben, Ghana

\section{Introduction}

In the 16th century, traditionally, village healers and clerics were the primary care givers offering herbal remedies (Modernghana.com, 2014). Herbalist provided treatment of illness in the local communities before and during the advent of Europeans (ibid). Western medicine was introduced by Christian's missionaries to the Gold Coast in the Nineteenth century (ibid). In 1893, a public work department was introduced to implement a working sanitation system for the colony. Finally, in 1880s, a medical department was formed bringing about an introduction to a formal medical care system consisting of a laboratory, branch of research, a medical branch of hospitals, clinics and the sanitary branch for public health (ibid). After the war, the central government made a concerted effort to expand western style medical facilities and after World War II, both the world health organization (WHO) and the United Nations children's fund (UNCF) had been active in providing money and support to provide additional western medical care in Ghana (Adoma-Yeboah, 2005).

In Ghana, most health care is provided by the government and largely administered by the Ministry of Health (MOH) and Ghana Health Services (GHS) (Asenso-Okyere et al, 1998). The Ghana health care system has five levels: Health post which is first level primary care for rural areas, health centre and clinics, districts hospitals, regional hospitals and tertiary hospitals (Ibid). These programmes are funded by the government of Ghana, financial credits, internally generated fund (IGF) and door-pooled health fund (Ibid). There are two hundred (200) hospitals in Ghana, but they provide less than $2 \%$ of health care services (Ibid). The urban centers are well served and contain most hospitals, clinics and pharmacies in the country. However, rural areas often have no modern health care. Patients in the area often rely on traditional African medicine or travel great distances for health care. In 2005, Ghana spent six point two percent (6.2\%) of GDP on health care or thirty US dollars (US\$30) per-capita of approximately thirty-four percent (34\%) of government expenditure (Adoma-Yeboah, 2005). Ghana has universal healthcare system that is the National Health Insurance Scheme (NHIS) and until this establishment, many people died because they did not have money to pay for their health care needs when they were sick. The system of health care which operated was known as "cash and carry" 
system which was initiated in 1985 largely in response to the structural adjustment programme (SAP) laid out by the IMF (Asenso-Okyere et al, 1998). Under this system, the health need of an individual was only attended to after initial payment before the service was made. Even in the cases when patients have been brought into the hospital on emergencies, it was required that money was paid at every point of service delivery (Ibid). When the country returned to democratic rule in 1992, its health care sector started seeing improvement in terms of: human resource improvement, service delivery and public education about health condition (Ibid). The idea of national health insurance scheme (NHIS) in Ghana was conceived by former president John Kuffour and then New Patriotic Party (NPP), who, when seeking the mandate of the people in the 2000 general elections promised to abolish the "cash and carry" system of health delivery (Modernghana.com, 2014). Upon becoming the president, he pushed through his idea of getting rid of the cash and carry system and replacing it with an equitable insurance scheme that ensured that treatment was provided first before payment (Ibid). Ultimately, the National Health Insurance Scheme (NHIS) was established under Act 650 of 2003 by the government of Ghana to provide a broad range of health care services to Ghanaians through districts mutual health insurance schemes (Criel 1998). One of the primary goals of Ghana's NHIS was to increase affordability, utilization of drugs and health services in general, among the poor and vulnerable population (Ibid p.74). The NHIS aims to assure equitable and universal access for all residents of Ghana to an acceptable quality package of essential health care services without payment being required at the point of use (Kwarteng, 2015). The ultimate goal of the NHIS is the provision of universal health insurance coverage for all Ghanaians, irrespective of their socio-economic background. The NHIS is based on District Mutual Health Insurance Schemes (DMHIS), which operates in all 230 districts of the country (Ibid).

The NHIS is financed by a national health insurance levy of $2.5 \%$ on certain good and services, $2.5 \%$ monthly payroll deduction being part of the contribution to the Social Security and National Insurance Trust (SSNIT) for formal sector workers, government budgetary allocation and donor funding (Adoma-Yeboah, 2005). But the formal sector workers will still have to pay a registration fee to a DMHIS for an identity card (ID) to be able to access health care services (Ibid). Contributions from members of the informal sector are also made to the NHIS with the minimum and maximum premium being seven point two zero (GH 7.20) and forty seven point seven zero (GH 47.70) Ghana cedis respectively (Ibid). However, the core poor, pregnant women, pensioners, people above the age of 70 and those below 18 years are exempted from premium payment (Asenso-Okyere, et al 1998). There is no any other cost sharing or co-payments with the NHIS, except the premium paid (Ibid). The benefit package of the NHIS consists of basic health care services, including outpatient consultations, essential drugs, inpatient care and shared accommodation, maternity care (normal and caesarean delivery), eye care, dental care, and emergency care (Ibid). About ninety five percent (95\%) of the diseases in Ghana are covered under the NHIS however, some services classified to be unnecessary or very expensive are on the exclusion list, among these are; cosmetic surgery, drugs not listed on the NHIS drugs list (including antiretroviral drugs), assisted reproduction, organ transplantation, and private inpatient accommodation (Asenso-Okyere et al, 1998).

A fee for service type of provider payment mechanism was used for paying health care providers initially, but this was replaced with the Ghana Diagnostic Related Groupings (GDRGs) in April, 2008 (Ibid). The reason for the replacement was that the fee for each service was found to be low and hence unattractive, especially for the private providers to participate (Ibid). Providers are encouraged to participate in the NHIS, in order to reduce congestions and delays for clients when seeking health care services, with the fee for service, providers were also required to submit detailed information on all services and charges for claims submissions, this involves a lot of paperwork which providers were not happy with, hence the GDRGs were introduced to help remedy some of these issues (Ibid). The tariff covers the full cost of the estimated direct consumables for direct patient care, anesthesia and other investigations (Ibid). The GDRGs also captures about eighty percent $(80 \%)$ of the estimated overhead cost for public health facilities, comprising of building and equipment maintenance, housekeeping and utilities (Ibid). It is expected that the new tariff will generate adequate revenue from the NHIS for providers to cover a significant portion of their cost of operation (Ibid). But, currently the NHIS is experimenting with capitation in the Ashanti Region of Ghana, to test its feasibility for scaling up, alongside the GDR (Ibid).

Since the inception of the NHIS, many studies have been carried out on the willingness and acceptability of the NHIS, the determinants of enrolment into the NHIS, and the health seeking behavior of insured clients, for instance, a study by Asenso-Okyere et al., found more than ninety percent (90\%) of the respondents agreeing to enroll in the NHIS and about sixty three point six percent $(63.6 \%)$ willing to pay a monthly premium of three point zero three US dollars (\$3.03) (Asenso-Okyere, et al 1998). On determinants of enrollment into the NHIS, it was also shown that individuals from poorer households were less likely to enroll compared with those from rich households (Ibid). However, there is limited knowledge on the influence of the NHIS on the behavior of health care providers; health care providers form an important segment of health care delivery (Ibid). Their (providers) behavior plays a significant role in determining 
whether the goals of a health system can be achieved (Ibid).

The main objective of the study was to come up with how the National Health Insurance came into being focusing on the challenges relating to the accessibility and the sustainability of the scheme in Ghana, and Ejisu-Juaben Municipal Assembly in particular. The specific objectives include: To come up with the historical evolution of the national health insurance scheme policy in Ghana, explore subscribers perceptions and opinions on the accessibility of the Ejisu-Juaben health insurance scheme and to identify the challenges that confront the scheme in the Ejisu-Juaben area. The others include examining the contribution of service providers in the provision of quality health care at the Ejisu. Analyse views on the sustainability of the health insurance scheme in Ejisu-Juaben Municipality and to determine the extent to which accessibility to health care has changed since the inception of the NHIS.

The efficiency and sustainability of the NHIS is based on the stakeholders (the scheme, service providers and the subscribers). The scheme is expected to ensure quick and timely disbursement of funds to providers. On the part of service providers, they must ensure proper service delivery to subscribers whiles the latter is expected to facilitate payment of premiums where necessary. The responsibilities of service providers are spelt out in sections 37(7) of the National Health Insurance Regulation, 2004 (L. 1 1809) follows: "A claim for payment of health care services rendered under a scheme licensed under this Act shall be filled within sixty calendar days from the date of the discharge of the patient or rendering of service". On the other hand section 38(I) of the L. I 1809 states: "A claim for payment of health care service rendered which is submitted to the scheme shall, unless there is any legal impediment, be paid by the scheme within four weeks after receipt of the claim from the health care facility".

It has been observed that, whilst health care facilities do honor section 37 (7) of L.I 1809, the schemes has not been able to comply with section 38(I) of the L.I 1809. This raises concern about the efficiency of the scheme. If the scheme owes some providers, the obvious and unanswered question is whether the scheme is sustainable enough to serve the needs of subscribers. Meanwhile, since the inception of the scheme, no or little assessment of its performance in the Ejisu-Juaben municipality has been undertaken. This study therefore seeks to explore the historical evolution of the National health insurance scheme, the challenges that confront the scheme from the perspective of service providers and subscribers, the effect of the scheme on beneficiaries in terms of equity and financial protection against economic cost of illness and access to health care services.

\section{Methodological Issues}

The study adopted a descriptive survey design using case study approach. The descriptive survey design is chosen because of its merits. It makes it possible to make generalization from a sample to a population so that inferences can be made about some characteristics or behavior of the population. This is important because the study is exploratory that allows for a careful investigation of a study or a case. The descriptive survey offered the chance of gathering data from a relatively large number of classes at a particular time so as to make inferences and generalizations from the study of the sample. It is essentially cross-sectional (Best \& Kahn, 1995; Gay, 1990; Osuala, 1993). Gay, (1990) perceives the descriptive survey as a research design that attempts to describe existing situations without actually analyzing relationships among variables. This design was chosen because it has the advantage of producing a good amount of responses from a wide range of people. It also provides a clear picture of events and people's behaviour on the basis of data gathered at a point in time.

The purposive and snowball sampling procedures were considered the best options for selecting the samples in this study. Purposive sampling enabled the researcher, first of all, to select ten communities spread across the district; and also to sample views from different categories of people with unique characteristics and location. This sampling technique enabled the investigators to target those perceived to have some important and useful information for the study. Thus, all persons in the targeted groups that were considered critical to the study were interviewed. The different groups that were contacted included the service providers, scheme management and subscribers. These groups of people were easily identified in their communities. Once one was contacted, the rest were reached through snowballing technique. They were contacted for consent to take part in the research.

In all, the study covered one hundred and twenty (120) respondents. This involved five management team members, fifteen (15) service providers and one hundred (100) subscribers. This sample size was chosen in order to have a number that was representative enough of the target population. Dealing with a smaller sample size might not produce results that were representative of the true situation in the locality since the communities were quite large. The data for the study were collected from hundred (100) subscribers (beneficiaries of the scheme) selected from ten (10) towns and communities drawn from both rural and urban settings. The communities were Ejisu, Asotwe, Akyewkroum, Juaben, Bomfa, Effiduase, Asokore, Dadiease, Ntunkumso, Seneagya. These communities were the major settlements and were chosen due to their strategic locations and significance in the municipality; they are scattered all over the municipality. Table 1 shows the distribution of the respondents selected from the various communities in the Ejisu-juaben 
Municipality.

Table 1. Distribution of respondents

\begin{tabular}{llll}
\hline Communities & Subscriber (Card bearers) & Service Providers & Management Staff \\
\hline Ejisu & 10 & 1 & - \\
Asotwe & 10 & 3 & - \\
Akyewkroum & 10 & - & - \\
Juaben & 10 & 2 & - \\
Bomfa & 10 & 1 & - \\
Effiduase & 10 & - & - \\
Asokore & 10 & 1 & - \\
Dadiease & 10 & 2 & - \\
Seneagya & 10 & - & 5 \\
Ntunkumso & 10 & 5 & 5 \\
Total & 100 & 15 & - \\
\hline
\end{tabular}

Source: Author's field work, 2015

At least ten subscribers were chosen from each of the ten (10) communities. All members of the scheme management team are at Ejisu, the head office of the EJHIS.

The review of secondary data also helped in obtaining information on the National Health Insurance Scheme, the Municipal Health Insurance Scheme and other mutual health insurance schemes in Ghana and elsewhere. The secondary sources included data from journals, reports, the internet and other publications. Interview guide was used to obtain information on a wide variety of issues on the topic. This also provided the researchers the opportunity to give further clarification and details in answering relevant questions. Data gathered from the field for the study were edited and coded to ensure that all inferring schedules were complete and contained accurate information. All questionnaires were given serial numbers to facilitate easy identification for scoring. Basic statistical tools on the Statistical Package for the Social Sciences (SPSS version 12.0), was used in the data analysis.

The study was beset with a number of challenges; nevertheless this did not affect the validity of the findings. The most significant challenges encountered included the fact that local residents seemed to exhibit "research fatigue". This was apparently prominent in Bomfa and Dadiease. Most of the participants lamented that no significant improvement had taken place in their living condition in spite of the numerous research work that had been conducted in the area, which they participated. There were frequent interruptions during the process of interviewing the participants, especially with some of the subscribers. They were often called to attend to one assignment or the other. This situation impeded or broke the smooth flow of thought of the respondents. Sometimes it became very difficult to get that particular respondent to continue with the interview, which resulted in the researcher spending more time or rescheduling the interview.

\section{Health Care Financing: Definitional Issues}

Countries adopt different strategies of collecting revenue to finance health care. Some of these methods are taxation, out-of-pocket payments, and social health insurance, among others. According to Ghana Statistical Service, nearly thirty percent (30\%) of global expenditure on health which was estimated at three point one trillion US dollars (US\$3.1) came from taxation; around twenty to twenty five percent (20-25\%) was from out-of-pocket payments and the same from social health insurance (SHI) contributions, another fifteen percent $(15 \%)$ by private insurance (Ghana Statistical Service 2003). From the World Health Organization (WHO), there is a wide variation in the sources of financing, Africans and Asian countries spent a lot from out-of-pocket payments than government general revenue or social health insurance as compared to European countries.

The World Health Organization posits that, health care system of a country is well shaped by the methods used in financing personal health care services. Personal health care includes services such as hospital care, physician care, dental services, and drugs that are provided directly to individuals (Ibid). How this care is financed influences how people access health care, types of health care provided and the mechanism used to allocate health care services. They added that financing methods also influence how the costs of health care are distributed or allocated to the people in the society by income and by health status.

According to Eric Kwarteng, the term health insurance is generally used to describe a form of insurance that pays for medical expenses. It is sometimes used more broadly to include covering disability or long-term or custodial care needs 
(Kwarteng 2015). Ghana's Ministry of Health, defines health insurance as an alternative health care financing system which involves resources pooling and risk sharing among members (Ministry of Health, 2003). It provides security against loss by illness or injury, financial protection against health related expenses and coverage for out-patient and in-patient care and other specialized type of care. It may be provided through a government-sponsored social insurance programme, or from private insurance companies (Ibid). It may also be based on group basis (e.g. by a firm to cover its employees) or purchased by individual consumers (Ibid). In each case the covered groups or individuals pay premiums or taxes to help protect themselves from high or unexpected health care expenses (Ibid). The Ministry of Health Further added that, similar benefits for paying for medical expenses may also be provided through social welfare programmes funded by the government. The benefit is administered by the central organization, most often either a government agency or private plan. National health insurance systems are founded in many countries, particularly in Europe. Systems of national insurance frequently co-ordinate with other national programmes of social insurance, such as pension programmes, programmes of unemployment insurance, and workers compensation (Criel 1998).

From Saltman, there are two major types of health insurance based on source of funding. These are private health insurance and public health insurance he defines private health insurance as a mechanism for people to make financial contributions to protect themselves from the potentially extreme financial cost of medical care if they become severely ill, and ensure that they have access to health care when they need it. Saltman, R.B. and Dubois argue that, purely private enterprise health care systems are comparatively rare (Saltman \& Dubois 2004). Where they exist, it is usually for a comparatively well-off sub population in a poor country with a poorer standard of health care for instance, private clinics for a small, wealthy expatriate population in an otherwise poor country (Ibid). They stressed that, there are countries with a major private health care system with residual public service (Ibid). Social security health care model is where workers and their families are insured by the state (Ibid). Kashner, Muller, Richter, Hendricks and Ray came up with two types of public health insurance. These are publicly funded health insurance scheme, where the residents of the country are insured by the state and social health insurance, where the whole population or most of the population is a member of a sickness insurance company (Kashner, 1998). They continued that a publicly funded health insurance is financed through taxation (Ibid). When taxation is the primary means of financing health care, everyone receives the same level of coverage regardless of their ability to pay, their level of taxation, or risk factors. Most developed countries currently have partially or fully publicly funded health systems (Ibid). Examples are the United Kingdom's National Health Service (NHS), or the Medicare systems in Canada and (Ibid) Australia (Ibid). Saltman included that, Social Health insurance (SHI) is financed through a (government mandated) social insurance programme based on the collection of funds contributed by individuals, employers, and sometimes government subsidies. Social security health care model may exist under social health insurance. This is when workers and their families are insured by the state (Ibid). SHI systems are characterized by the presence of sickness funds which usually receive a proportional contribution of their members' wages. With these insurance contributions, these funds pay medical costs of their members, to the extent that the services are included in the, sometimes nationally defined, benefit package (Saltman \& Dubois 2005). Affiliations to such funds are usually based on professional, geographic, religious/political and/or non-partisan criteria (Ibid). Usually, there are user fees for several health care services to inhabit usage and to keep social health insurance affordable (Ibid). Otto von Bismarck was the first to make social health insurance mandatory on national scale (in Germany), but social health insurance was already common for many centuries before among guides mainly in continental Europe (Ibid). Countries with SHI systems include Austria, Belgium, Germany, France and Luxemburg. Generally, their per capita health expenditures are higher than in tax-based systems (Ibid).

The nature of health care financing systems varies widely across developed counties. With the exception of the United States and South Africa, all of the developed countries have implemented some kind of national health insurance system; that is, they have established programmes to ensure that the majority of their citizens have access to health care services with minimal cost-sharing (Ibid). From the World Health Organization, some countries (such as Germany and France) require employers to offer and employees to purchase a health insurance plan with payroll taxes as the major source of funding for this (Ibid). In other countries such as Canada general tax revenue supplies the major source of funding for their health insurance (World Health Organization 2008). Saltman noted that, health insurance in Canada is administered by each province, under the Canada Health Act, which requires all people to have free access to basic health service. Collectively, the public provincial health insurance systems in Canada are frequently referred to as Medicare (Saltman \& Dubois 2005). He added that private health insurance is allowed, but the provincial governments allow it only for services that the public health plans do not cover; for example, semi-private or private rooms in hospitals and prescription drug plans (Ibid). Canadians are free to use private insurance for elective medical service such as laser vision correction surgery, cosmetic surgery, and other non-basic medical procedures (Ibid). According to World Health Organization, about sixty percent $(60 \%)$ of Canadians have some form of supplementary private health insurance; many of them receive it through their employers (Ibid). Private sector services are not paid for by the government accounts for nearly 30 percent of total health care spending. In 2005, the supreme court of Quebec ruled, in 
Chaoulli v. Quebec, that the provinces prohibition on private insurance for health care already insured by the provincial plan could constitute an infringement of the right to life and security if there were long wait times for treatment as happened in this case. Dubois also added that, certain other provinces have legislations which financially discourage but do not forbid private health insurance in areas covered by the public plans (Ibid). The ruling has not changed the entire pattern of health insurance across Canada but has spurred on attempts to tackle the core issues of supply and demand and the impact of wait times.

Goodman and Waddington added that, the UK's National Health Insurance (NHS) is a publicly funded healthcare system that provides coverage to everyone normally resident in the UK (Goodman \& Waddington 1994). It is not strictly insurance system because there are no premiums collected, costs are not charged at the patient level and costs are not paid from the pool (Ibid). From The World Health Organization, the costs of running the NHS (one hundred and four billion Euros in 2007 to 2008) are met directly from general taxation (Ibid). They added that, private health care has continued to operate parallel to the NHS, paid for largely by private insurance, but it is used by less than eight percent (8\%) of the population, and generally as a top up to NHS services (Ibid). The NHS provides the majority of health care in the UK, including primary care, inpatient care, long term health care, ophthalmology and dentistry. The WHO again noted that, recently the private sector has been increasingly used to increase NHS capacity despite a large proportion of the British public opposing such involvement (Ibid). According to the World Health Organization, government funding covered eighty six (86\%) of overall health care expenditures in the UK as of 2004, with private expenditures covering the remaining $14 \%$ (Ibid).

\section{History of Health Insurance in Ghana}

According to Adoma-Yeboah, Ghana is one of the few countries in Africa that has taken bold steps towards early efforts to establish Health Insurance Scheme in Ghana. He added that the search for an alternative means of financing and provision of sustainable and affordable health care service for Ghanaians has been among the priorities of successive governments since independence. Between 1960 and 1966, a nationwide health insurance funded from tax revenue was introduced in Ghana. (Adoma-Yeboah, 2005). Free health services were made available at all the country's healthcare facilities. Again, in 1970, a committee headed by Dr. Konotey Ahulu was constituted to make proposals for the introduction of a health insurance scheme (Ibid). This led to the enactment of the Hospital Fee Act 387 of 1971, which replaced the free health scheme initiated during the first Republic (Ibid). However, the process of establishing a health insurance scheme for the country was aborted following the 1972 military coup (Ibid). The preparation of legislative instrument to operationalize the Hospital Fee Act 387 of 1971 started during the Third Republic but was once again thwarted by the military regime of 1983 (Ibid).

Adoma-Yeboah further discussed that, in July 1983, when Ghana's economy was on the verge of collapse, the then Provisional National Defense Council(PNDC) government introduced partial cost of health services through the enactment of the Hospital fee Regulation which was later updated by L.I 1313 OF 1985, the government initiated studies into alternative means of financing healthcare by entering into bilateral technical assistance contract with a German firm that would have studied the feasibility of creating a National Health Insurance Programme (Ibid). This could not materialize and a local consultant was engaged to carry out the studies whose report was also not followed up.

In 1997, the Ministry of Health set up its first Directorate for National Health Insurance scheme; this resulted in setting up of the Ghana Healthcare Company by the Social Security and National Insurance Trust (SSNIT) to provide other sources of health financing (Adoma-Yeboah 2005). Another effort was made by the Ministry of Health to pilot a health insurance scheme in Koforidua in the Eastern Region which did not start (Ibid). However, health insurance scheme were set up in the urban areas of the country by some private for profit insurance companies. Vanguard Assurance Company instituted a scheme with the Association of Private Medical Practitioners as providers; Metropolitan Insurance Company formed the Medicare Health Insurance Scheme (Ibid).

Adoma-Yeboah again noted that, consequently, some of these schemes are reorganizing; following the passage of the national health insurance law whilst others have wound up. Gemini Life Insurance Company (GLICO) is also setting up a private mutual insurance scheme (Ibid). Some other non-private health insurance schemes such as the mutual health organization at Nkoranza, Damango, Tano, Jaman and Dagme West district and others mostly supported by Non-Governmental Organisations and religious bodies in various part of the country, especially the rural areas sprang up (Ibid).

According to the Ministry of Health (MOH), in April 2002, the ministry came out with a policy framework to guide the implementation of District -Wide mutual health Organizations (Ibid). It selected Fourty five (45) districts throughout the country including the existing Mutual Health Organizations, to pilot the National Health Insurance Scheme (Ministry of Health, 2003).

From Adoma-Yeboah, the current health insurance scheme operating in the country was established in 2003 during the 
Ex-President Kuffour's administration by an Act of Parliament, Act 650 to replace out-of-pocket payment at the time of health service use (Adoma-Yeboah, 2005). The Act makes it mandatory for all residents in the country to belong to a health insurance scheme (Ibid). He again noted that, two types of health insurance are in operation namely the social and private health insurance schemes. Under the private, there are the Private Mutual Health Insurance Scheme (PMHIS), and The Private Commercial Health Insurance Schemes (PCHIS) (Ibid). The DMHISs now established in two hundred and thirty (230) districts of the country to serve as a strategy for delivering its pro-poor policy to the under privileged segment of the society. The DMHISs incorporate members from both formal and informal sectors (Ibid). Ghana News Agency Reported that, total registered members to the scheme in Ghana was eleven million two hundred and seventy nine thousand, six hundred and seventy eight $(11,279678)$ as at the end of 2007, representing fifty five percent $(55 \%)$ of the population and total active membership was nine million, seven hundred and seventy-three thousand, one hundred $(9,773,100)$ members as at the end of 2007 , representing forty eight $(48 \%)$ of the population (Ibid). Members of the scheme contribute according to the ability to pay and package of health services cover of over ninety five percent (95\%) of diseases afflicting Ghanaians. There is differential contribution level both in the formal and informal sectors of the society. The formal sector workers contribute two point five $(2.5 \%)$ of their seventeen point five percent $(17.5 \%)$ social security and National Insurance trust (SSNIT) contribution whereas informal sector workers contribute at least seven cedi twenty pesewas per annum (Ibid). The contribution levels have an inbuilt cross-subsidization mechanism whereby the rich pay more than the less privileged, adult pay on behalf of children, the healthy cover the sick and the urban dwellers pay more than the rural dwellers (Ibid). Children less than 18 years and adult above seventy (70) years are covered free of charge (Ibid). Contribution level of the people is categorized based on their socio-economic stratification. The policy has grouped Ghanaians into six main categories: core poor, very poor, middle income, rich and very rich (Ibid). All these categories of people pay in line with their ability to pay. The state instituted a two point five percent $(2.5 \%)$ National Health Insurance Levy, payable on selected goods and services. Funds raised from this source are used to subsidize the contribution of the underprivileged in society and to pay for the contribution of the core poor and other vulnerable groups (Ibid).

Service providers within the public, private and mission sectors provide the benefit package under the scheme after satisfying accreditation criteria. As at December 2007, all the Public Healthcare Providers, and 800 Private Healthcare Providers have been accredited. For a period of two years (2005 to 2007), utilization of healthcare facilities under the scheme increased from three million, two hundred and thirteen thousand, four hundred and fifty to six million, eight hundred and thirty five thousand, one hundred and four $(3,213,450$ to 6,835,104) (Adoma-Yeboah, 2005). A gatekeeper system is in place as a cost control measure. Gatekeeper system is a system which ensures that a visit to the secondary and tertiary health facilities is by referral from a primary health facility (Ibid). These are not of district focus. They are either community-based or occupational or faith-based (Ibid). Goldfields Mutual Health Insurance Scheme (GMHIS) established in 2007 by the Goldfield Ghana Limited for the employees of the company is a typical example. These schemes do not receive subsidy from the government (Ibid).

According to Goodman, H., and Waddington, C., there are many sources of funds that are exploited by people and states for caring for health. They noted that, the available sources of funding include user fee, state (public) funded, direct transfers and grant (Ibid). User fee otherwise called (Out-of-pocket payment-OPP) is a charge imposed on a patient or anyone who accesses health service. The fee could be for the consultation, drugs, dressing and diagnostic tests or all of these things. Since people are willing to pay for a cure, fees are mostly charged for curative service in the form of drugs and injections (Goodman \& Waddington, 1994). Kashner, et al, (1998) added that, in many countries, especially in developing countries, the out-of-pocket payments form a major part of the total health expenditure. It is estimated that in sixty percent $(60 \%)$ of countries with incomes below one thousand US dollars (US\$1,000) per capita, OPP constituted fourty percent (40\%) or more of the total health expenditure, whereas only thirty percent (30\%) of middle-and high-income countries depended on this kind of financing (Kashner et al, 1998). While people have the freedom of choice for paying out-of-pocket for health expenditure, and it might provide high satisfaction to the rich in society, there is no guarantee that the majority of the population would be able to afford health care costs through OPP. The real issue in many developing and even in developed countries is that the imposing user fee at the time of service provision sometimes hinders utilization of health services. Kashner et al, argued that, people become impoverished due to the higher and/or rising costs of medical bills, because of the uncertainty of the amount of expenditure needed to meet the health care needs on an individual basis. In some cases, people have to incur 'under-the-table' expenditure for getting access to public health facilities (Ibid). And, in other cases, the unskilled and unqualified private providers might exploit people by charging higher rates for their services. In order to protect the poor, a strong stewardship of government is required to rationalize the provider-consumer relationship (Ibid). According to kashner et al, in Ghana, the Hospital Fee Decree (1969), later amended into the Hospital Fee Act (1971) and the Hospital Fees Regulation 1985 (L. I. 1313), introduced forms of payment for health care delivery in public health facilities in the country (Ibid). These Acts specified fees to be charged for consultation, laboratory and other diagnostic procedures, medical, surgical and 
dental services, medical examination and hospital accommodation in Ghana. The L. I. 1313 was introduced mainly to enable hospitals to totally recover all costs (except staff wages) involved in their operations and was highly successful in ensuring availability of medicines and medical supplies (Ibid). Kashner et al, T., M., Muller however, observed that, it lacked 'human face' and led to huge reduction in uptake of services as well as refusal of health professionals to treat patients, including those requiring emergency care, without up-front payment. However, an exemption scheme was introduced alongside the cost recovery to care for the poor and vulnerable (Ibid). According to the National Health Insurance Scheme, the scheme was subject to abuse, misinterpretation and arbitrary implementation. Absence of clear guidelines, lack of monitoring and supervision, transparency, ownership and knowledge of these schemes by heads of institution all contributed to the failure of the system (Ibid). That is, there was no conscious system designed to prevent possible financial leakage. In the ensuing years standard of health care provision fell drastically. There was acute shortage of essential drugs in all public health facilities (Saltman \& Dubois 2004; Asenso-Okyere et al 1997).

According to Asenso-Okyere et al, following a chronic shortage and irrational use of drugs within the public health system, the government of Ghana introduced a national drug revolving fund scheme known as 'cash and carry'(Ibid). The scheme was aimed at allowing the Ministry of Health to provide efficient pharmaceutical services at health facilities in the country. The scheme was piloted in the Greater Accra and Volta Regions in 1990 and extended to the entire country in January 1992 (Ibid). Initial seed capital in terms of free drugs through the Central Medical Stores was provided to the government health facilities by the Ministry of Finance and Economic Planning. The health facilities were expected to sell the drugs to patients and the proceeds used to buy more drugs under a revolving fund scheme. This strategy brought about considerable improvement of drugs supply situation in the country (Ibid). As at May 1992, twenty two (22\%) of the items on the essential drugs list were available at Central Medical Stores. This rose to sixty two percent $(62 \%)$ in June 1993, after eighteen months of nationwide implementation of the cash and carry. It is worth noting that, before the introduction of health insurance, $80 \%$ of health financing in the public health sector was through tax revenue and donor funds. The remaining $20 \%$ was from internally generated funds through the 'cash and carry' system. The cost sharing measures were introduced into the education and health sectors as part of Ghana's economic reforms which began in 1983 (Ibid). Under the cost recovery legislation for health sector, fees differ by type or level of facility, treatment, location, age, nationality and type of service provided (Asenso-Okyere et al 1997).

Asenso-Okyere et al, states that, before the introduction of the 'cash and carry' in public health facilities, private health care facilities in Ghana was operating on full cost recovery. Mission health care facilities and other non-governmental organizations charged patients with the aim of covering part of their operational costs, especially recurrent expenses. Traditional and spiritual practitioners also operate some form of cost recovery (Ibid). However, the cost recovery of the traditional and spiritual practitioners often term as 'thanks offering' is informal (Asenso-Okyere et al 1998).

Goodman and Waddington have structured user fee for curative care into three categories. The user fee charged on the actual cost plus a percentage mark-up of the drugs and dressing received (Ibid). In this instance, the patient pays for exactly what is received and there are no hidden subsidies in the price. This system makes fees for treatment differ from patient to patient depending on treatment that would be received. Patients therefore have no idea in advance what they would have to pay for their treatment. Monitoring and supervision of money and drugs become difficult for service providers due to different fees for patients (Ibid). The user is charged a fixed price for treatment received. This could be done in two ways; (a) Charging the same fee for all diagnosis, and (b) diagnosis categorized into a small number of groups and each group has its own fee (Ibid). Under the first scheme, a patient with malaria would pay the same as patient with pneumonia. With the second scheme, if malaria and pneumonia were in different diagnostic groups, the two patients would pay different fees. Charging for different diagnostic groups allows for the fact that some conditions are much more costly to treat than others (Ibid). The system allows for only a small number of possible fees to pay and is therefore simple to administer. It also allows more expensive treatment to be subsidized by cheaper treatments. However, patients pay more than the cost for simple treatments (Ibid). The patient is charged a fixed fee per episode of illness. In this case, a fixed fee is paid on the first visit and nothing is paid further in the subsequent visits (to the same health facility) relating to the original diagnosis (Ibid). However, different fee is charged for unforeseen complications. This charging method makes cross-subsidization of treatment possible. Prices and fees for treatment are displayed in advance. If there is no improvement in their condition, they could return to the health facility without paying additional money (Ibid). Publicly funded health care supporters of publicly funded health care claim that publicly funded health care has several advantages over free market provisions (Ibid). Studies have found that private for-profit hospitals are more expensive and have higher death rates than private not-for-profit hospitals (Asenso-Okyere et al 1998). The researchers attribute these patterns to the for-profit nature of the hospitals. The quality of health maintenance organizations and managed care has also been criticized by proponents of publicly funded health care (Ibid). According to a study by the World Health Organization, publicly funded systems of industrial nations spend less on health care and enjoy superior population-based health care outcomes (World Health Organization 2002). 
Advocates of public funded health care claim that the United States of America, which has a partial free market health care system, spends a huge proportion of its GDP on health care (15\% more than many countries) (Ibid). It is further claimed that the need to provide profits to investors in a predominantly free market health system, and the additional administrative spending, tends to drive up costs, leading to more expensive health care provision. Some studies have found that private for-profit hospitals are more expensive and have higher death rates than private not-for-profit hospitals. The researchers have attributed this to the for-profit nature of these hospitals (Glesne 2005).

Commentators on the political left argue that a publicly funded health care system is inherently superior because health care is seen as a human right and argue that access to health treatment should not be based on ability-to-pay (Ibid). The profit motive in medicine is also criticized as valuing money above public benefit. For example, pharmaceutical companies have reduced or dropped their research into developing new antibiotics, even as antibiotic-resistant strains of bacteria are increasing, because there's less profit to be gained there than in other drug research (Ibid).

Opponents of publicly funded health care, predominantly on the political right, have pointed out a number of flaws in publicly funded health care systems, such as those which operate in Canada, the United Kingdom and Germany (Glesne 2005). Public health care systems have been criticized for poor quality of care, long waiting lists, and slow access to new drugs. International comparisons of health care quality are difficult and have yielded mixed results. However, an international comparison of health systems in six countries by the Commonwealth Fund ranked the UK's publicly funded system the overall best and first in quality of care. Systems in the United States and Canada tied for the lowest overall ranking and toward the bottom for quality of care (Ibid). Overall, Canadians are quite satisfied with the quality of health care they receive. In a regularly conducted opinion poll, seventy percent (70\%) of Canadians reported that they were either very satisfied or somewhat satisfied with the quality of care they receive compared to thirty percent (30\%) being somewhat dissatisfied or very dissatisfied. The main factor of dissatisfaction is waiting times, Canadians are more likely than citizens of most other developed countries to experience long waiting lists for medical care, and that access to doctors is comparatively difficult; the study criticized the Canadian model of universal health care (Ibid). Public health care varies significantly from country to country. Many countries allow for private medicine in addition to the public health care system. Some countries, e.g. Norway, have more doctors per capita than the United States. Also, the US does not have any official record for waiting lists, but a 2005 survey by the Commonwealth Fund of sick adults in six nations found that only forty seven percent (47\%) of US patients could get a same- or next-day appointment for a medical problem, worse than every other country except Canada (Ibid).

It has also been noted that the largely free market system of health care in the United States has led to the faster development of more advanced medical treatment and new drugs, and that cancer patients in the United States for many forms of cancer, including those of the breast, thyroid and lung, have higher survival rates than their counterparts in publicly-funded health systems in Europe (Ibid). Some analysts have pointed out the difficulty of comparing international health statistics. In particular, the mortality rates for cancer in the United States is at about the same level as many other countries, suggesting that the higher survival rates are a function of the way cancer is diagnosed. Many have theorized that public care systems, in which there is more bureaucratic government involvement and less financial incentive in the health care industry, lead to less motivation for medical innovation and invention (Glesne and Peskin, 1992).

Some commentators have pointed out that in publicly funded systems; health care workers' pay is often unrelated to quality or speed of care (Ibid). Thus very long waits can occur before care is received. There is also less financial motivation for the most able people to enter health care professions. For example, in Canada, which has a broad publicly-funded health system, the average physician earns only forty two percent (42\%) of the annual salary earned by their counterparts in the United States; this has led to long waiting lists for care (17.8 weeks in 2006) (Ibid). This difference in physician income reflects Canada's more limited spending on health care overall; in 2004, combined public and private spending on health care consumed fifteen point four (15.4\%) of U.S. annual GDP; in Canada, nine point eight percent $(9.8 \%)$ of GDP. By limiting the amount of money in the health care system through political mechanisms, shortages of health care resources (such as physicians, nurses, medical equipment, medical devices, pharmaceuticals, and hospitals) are more likely to occur (Glesne, 2005). Opponents claim that higher salaries constitute an incentive to enter the profession and attract more qualified individuals who would otherwise choose a different profession (Ibid).

Another possible criticism of publicly-funded systems cites the fairness of paying for people's poor individual decisions (smoking, drinking, drugging, etc.) as they relate to health care costs. It is argued that these costs should be incurred solely by those making those poor decisions (Ibid). Some American commentators have opposed publicly-funded health systems on ideological grounds, as they argue that public health care is a step towards socialism and involves extension of state power and reduction of individual freedom (Ibid). Direct transfers and grants refer to the provision of a quantity of resources, whether money or supplies, which does not have to be repaid (Ibid). The quantity of the transfer or grant 
will usually have been negotiated in advance, and it might be regular payment or a one-off gift. Grants, in particular, are often made on condition that they are utilized in a particular way, or that the money is spent on specific aspects of health programme, as determined by the donor (Goodman \& Waddington 2004). An example is the British government pledge of forty two point five million pounds (£42.5) sterling support of the government of Ghana policy of free medical care for pregnant women under the National Health Insurance Scheme (Daily Graphic 2008). Another example of a direct transfer could be the Ministry of Health providing money for the salaries of health workers, or a supply of drugs. An external donor agency might provide capital grant for the purchase of vehicle (Ibid).

There are many models of health insurance systems, but for the purpose of this study three main models have been identified. In distinguishing between the models, Huber et al identifies the two extremes of the systems as the mutualistic or participatory model and the provider-driven or technocratic models (Ibid). According to Huber et al, in Mutualistic or participatory models, Communities organize themselves to establish a health insurance system. In a process of participatory bottom-up planning, priorities are defined and important decisions, such as determining the benefit package, are taken by the communities (Ibid). The beneficiaries own and manage the system themselves and therefore are the financial risk bearers (Ibid). A contract is signed between each individual and all the others. They collect the premiums to cover the types of care previously defined and provided by facilities contracted (Ibid). The insurer and the care provider negotiate the terms of care (Ibid). Well-functioning schemes may play a strong role in defending the interests of households they represent. They can negotiate for better quality, such as better availability of essential drugs, or improved provider behavior (Ibid).

According to Huber et al, Provider-managed schemes are often initiated by a hospital that is concerned about securing a stable source of revenue in a context where many patients cannot pay the bills. The health care provider is the insurer and manager of the scheme and is therefore the financial risk bearer (Huber, Hohmann and Reinhard, 2002). No intermediary structure exists between the payer of the fund and the health care provider (Ibid). Priorities like defining the benefit package are usually set in a process of top-down planning. The community plays only a negligible part in the process (Ibid). In some examples, a genuine concern to raise people's access to care can be the driving factor (Bwamanda / Democratic Republic of Congo) (Ibid).

He added that, the community often perceives this technocratic top-down management approach unfavorably. The non-involvement of the community may lead to a suspicious and distrustful clientele that is likely to show all features of moral hazard behavior (Ibid). The little contact with the knowledge of the grassroots membership does not allow for necessary adjustments like taking consumer interests more into account (Ibid). An additional aspect of a provider managed health insurance is the intention to raise the hospital revenue. In consequence this may attract patients to prefer hospital services like the outpatient department instead of encouraging them using primary health care services for basic pathologies (Ibid).

Another arrangement covering health risks is prepayment. Prepayment schemes are usually organized by health care providers. Risks are not shared with other community members as in insurance schemes (Ibid). A certain payment is made in advance to a health care provider or health care institution. At every consultation the prepaid amount is gradually debited, according to the consultation fee charged until the total amount is consumed (Ibid). It allows the purchase of health care at a time when money is available in the household. More expensive events like hospital admissions are difficult to finance with this model. In this arrangement micro credit schemes, which are involved in individual and collective income-generating activities, include an insurance component. In case of more serious illness, the insurance prevents the misuse of the loan for paying health bills, in which case the creditor could not pay back the credit (Huber, Hohmann \& Reinhard 2002).

\section{Health setting in Ghana}

In 1996 Ghana moved in a new wave of reforms when it implemented the Sector-Wide Approach as a charter for accelerating access to health services. The general course of the health sector reforms may be summed up in a mission statement contained in the Medium Term Health Strategy (MTHS) which states that

As one of the critical sectors in the growth and development of the Ghanaian economy, the mission of the health Ministries, Departments and Agencies is to improve the health status of all people living in Ghana through the development and promotion of proactive policies for good health and longevity; the provision of universal access to basic health service and provision of quality health services which are affordable and accessible. These services will be delivered in a humane, efficient, and effective manner by well trained, friendly, highly motivated and client oriented personnel (Center for Health and Social Services 2011).

Established on this and the bearings provided in the MTHS, the Ministry of Health advanced and published three to five year programmes of work in 1997-2001, 2002-2006 and 2007-2011. The various documents led to the achievement of 
some important indicators during each of the MTHS life period. In 1997-2001 was improving donor coordination and country-led health systems. During those years the major health systems indicators achieved were founding of health sector common funding instrument (the common basket) and configuration and management of reserved and direct project funds, entrenched common administration procedure, entrenched health partners' summit and coordination mechanisms, entrenched relief records as adopting sector-wide priorities, established sector-wide performance indicators, entrenched full annual reviews and improvement of sector-based annual sector plans, undertook valuation and authorization of Business Management Centers (BMCs) to encourage operative accounting and transparency, passed the Ghana Health Service and Teaching Hospitals Act 525, 1996,established the Ghana Health Service, established the Private Sector Unit and the coalition of NGOs in Health, adopted a national Capital Investment and Procurement Planning System, introduced the District Health Systems strengthening initiative and the District Health System Operations in-service training framework, developed and continued EPI coverage and presented quality of care standards and protocols, introduced the exemptions system for expectant mothers and the aged, negotiated for the retention of Internally Generated Funds within health facilities, introduced the additional duty hours allowance, introduced the Tema mechanical shop revolving fund, established the Food and Drugs Board and Undertook the five year MTHS review (Center for Health and Social Services 2011).

Also in the year 2002-2006 the theme was consolidating the gains and bridging the equities gap. The major health systems indicators achieved were consolidated the systems under Sector Wide Approaches(SWAP), expanding the Common Basket, decreasing reserved assets and support the harmonization boards within the changing environment including responding to the Highly In-Indebted Poor Countries Initiative, passed the National Health Insurance Act 650 and LI 1809, established the National Health Insurance Fund and Council, established the District Mutual Health Insurance Schemes, passed the Act and established the Ghana College of Physicians and Surgeons, introduced the Community-based Health Planning and Services (CHPS) ,initiative as part of the District Health Systems Initiative, introduced the staff cars allocation and repaid payment system as part of the staff retention strategy, introduced Common Management Arrangement II, as well as Undertook the five-year MTHS review (Ibid).

Again in 2007-20011 the theme was creating wealth through health and some of the major health system indicators achieved were increasingly migrated from the Common Basket toward Government Budget Support and Sector Budget Support with enlarged reserved financing, introduced the Regenerative Health and Nutrition program as a main health sector strategy, introduced the High Impact Rapid Delivery program for maternal and child health, Fused the implementation of the National Health Insurance Scheme, and introduced Common Management Arrangement III (Ibid).

With the passing of Act 525, the responsibilities of health service delivery were consolidated within GHS. According to $\mathrm{MOH}$, there was not a great deal of actual separation of service provision, and in order to fully carry out the Ministry's duty of policy formation and regulation oversight, there was a need to rethink the role of MOH in Ghana's health care delivery system.

The second governmental body that works with health care in Ghana is GHS, an "autonomous Executive Agency responsible for implementation of national policies under the control of the Minister for Health through its governing Council - the Ghana Health Service Council. The GHS "continues to receive public funds and thus remains within the public sector". This organization is the service provision arm of the health care system in the country, and works to implement national health care policies, provide health care services and manage resources for health care delivery. There are three administrative levels of GHS and five functional (service distribution) levels of health care in Ghana (Pehr, 2010).

Health Administration in Ghana is divided into three administrative levels: the national, regional and districts levels. It is further divided into five functional levels of national, regional, district, sub district and community levels. All the levels of administration are organized as Budget and Management Centers (BMCs) or cost centers for the purpose of administering funds by the Government and other stakeholders. There are a total of two hundred and twenty -three functional BMCs and one hundred and ten Sub-Districts BMCs. With the headquarters of the Ghana Health Service (GHS) also managed as a BMC, there are ten Regional Health Administration, eight Regional Hospitals, one hundred and ten District Health Administrations and ninety-five District Hospitals. All of these are run as BMCs. (Salisu and Prinz, 2009)

\section{Types of Health Insurance in Ghana}

There are three main categories of health insurance in Ghana. These include District Mutual Health Insurance Scheme (DMHIS), Private Commercial Health Insurance Scheme (PCHIS), and Private Mutual Health Insurance Scheme (PMHIS). The district mutual health insurance scheme is the first and most popular and is operational in every district in Ghana. This is the public or non-commercial scheme and anyone resident in Ghana can register under this scheme. If 
you register in 'District A' and move to 'District B', you can transfer your insurance policy and still be covered in the new district. The district mutual health insurance scheme also covers people considered to be indigent that is too poor, without a job and lacking the basic necessities of life to be able to afford insurance premiums. Apart from the premium paid by members, the district mutual health insurance schemes receive regular funding from central government. This central government funding is drawn from the national health insurance fund. Every Ghanaian worker pays two and a half percent of their social security contributions into this fund and the VAT rate in Ghana also has a two and a half percentage component that goes into the fund (Ghanaweb.com 2014). There are also the private commercial health insurance schemes operated by approved companies. One can access this type of health insurance by purchasing health insurance in any of such companies. Commercial health insurance companies do not receive subsidy from the National Health Insurance Fund and they are required to pay a security deposit before they start operations (Ibid). The third category of health insurance is known as the private mutual health insurance scheme. Under this type of health insurance any group of people for instance members of a church or social group can come together and start making contributions to cater for their health needs, providing for services approved by the governing council of the scheme. Private mutual health insurance schemes are not entitled to subsidy from the National Health Insurance Fund.

\section{Ghana's Health Financing}

To address the financial constraint for the poor and improve in equity in access to health care, Ghana passed a National Health Insurance law in 2003 (GOG 2003), mandating the establishment of District-wide mutual health insurance schemes (DMHIS). The act mandate that all district schemes must charge a minimum premium of roughly eight US dollars (US\$8) per adult for non-social security and National Insurance Trust (SSNIT) contributors to cover their premium. Those aged under eighteen (18), over seventy (70), pensioners, pregnant women and deemed indigent (core poor) are exempted from premium payments. The NHIS in its design has an in-built mechanism for equity in financial contributions with subscribers paying income adjusted premium. In practice, however, subscribers pay a flat rate because incomes are hard to assess. There is no cost-sharing beyond the premium; members do not pay any co-payments or deductibles. All SSNIT contributors, most of whom are formal sector employees have their premiums collected at the central level via pay-roll deductions of two point five percent $(2.5 \%)$ of SSNIT contributions which are proportional to income. However, they still have to pay a registration fee at a DMHIS to receive a card in other to be enrolled and to access benefits. Enrollment is legally mandatory but is facing non-compliance, as it is a social policy that is difficult to enforce, given the large informal sector for which there is no database and the need for formal sector workers (SSNIT contributors) to voluntarily pay a registration fee to be enrolled (MOH 2009). Beyond the premiums collected locally, the NHIS is financed through a National Health Insurance Levy instituted by the Government. This two point five percent (2.5\%) value added tax (VAT) is collected on most goods and service, but basic goods and foodstuffs predominantly consumed by the poor are exempted.

The National Health Insurance Authority (NHIA) mandates a pre-defined benefits package that covers ninety five percent $(95 \%)$ of the disease burden in Ghana. Services covered include outpatient consultations, essential drugs, inpatient care and shared accommodation, maternity care (normal and caesarean delivery), eye care, dental care and emergency care. The DMHIS contract accredited providers (public, private and church-based) to deliver services to its members and reimburses them after submission of claims for services. This system separates the purchasing and provision functions across different stakeholders to increase transparency. Currently the NHIS reimburses providers based on the Ghana Diagnostic Related Groupings (G-DRGs) and fee-for-service (FFS) for medicines using medicines tariff list (MOH) at the centralized level, the NHIS is regulated by the NHIA which also plays a key role in guiding Management of the National Health insurance Fund (NHIF). Revenues from the NHIF are used to provide reinsurance Schemes (DMHIS) and premiums for exempt groups.

\section{Socio-demographic information of respondents from Field Work}

The study participants comprised hundred (100) subscribers, fifteen (15) service providers and five scheme managers. The scheme managers are all based in Ejisu, the head office of the Municipal Health Insurance Scheme (MHIS). The health service providers were selected from various towns and communities where the health facility has been accredited by the scheme to provide health services. All the five scheme management team members who took part in the study were males and females who had served in the scheme for two to six years. They indicated that they have been educated to the tertiary level. All the five members of the scheme management team were relatively young: two of the management team members indicated their ages to be within twenty to twenty- nine (20-29). Two (2) indicated their ages to be within thirty to thirty nine (30-39) and the remaining one was within forty to forty nine (40-49) age groups. Coincidentally, those within the twenty to twenty nine (20-29) age groups were those who indicated that they were not married.

On the other hand, the ages of the card-bearers cut across all the age groups. Thus seven people representing seven percent $(7 \%)$ were under twenty (20) years, while ten percent (10\%) representing ten (10) people were above sixty (60) 
years old. From Table 2, majority of the subscribers who took part in the study were from two age groups of twenty to twenty nine (20-29) and thirty to thirty nine (30-39) representing thirty three percent (33\%) and thirty percent (30\%) respectively. On the whole, the youth constituted seventy percent $(70 \%)$ of the respondents. This implies that the resources of the scheme might not be overstretched since the youth are less prone to sickness.

Table 2. Age Distribution of Subscribers

\begin{tabular}{ll}
\hline Age & Percent \\
\hline under 20 & 7 \\
$20-29$ & 33 \\
$30-39$ & 30 \\
$40-49$ & 12 \\
$50-59$ & 8 \\
60 and above & 10 \\
Total & 100 \\
\hline
\end{tabular}

Source: Authors Fieldwork, 2015

However, none of the service providers' age was under thirty (30) years. Table 3 shows that the majority of the providers were within the age groups of forty to forty nine (40-49) representing fifty three point four percent $(53.4 \%)$ and fifty to fifty nine (50-59) representing thirty three point three percent (33.3\%) respectively. It could be said that the majority of the service providers were matured and experienced and for that matter are likely to provide quality health care. It was found out from the study that a majority, which forms fifty-five percent $(55 \%)$ of the subscribers were married as against thirty-eight (38\%) who indicated that they were single, while the remaining $7 \%$ were made up of those individuals who were 'widowed' or 'divorced ( Table 4)

Table 3. Age distribution of service providers of the scheme

\begin{tabular}{lcc}
\hline Age & Frequency & Percent \\
\hline $30-39$ & 2 & 13.3 \\
$40-49$ & 8 & 53.4 \\
$50-59$ & 5 & 33.3 \\
Total & 15 & 100.0 \\
\hline
\end{tabular}

Source: Authors field work, 2015

Since the majority of the subscribers were married, it could imply that their dependents aged below 18 years were also beneficiaries of the scheme. These minors benefitted from the scheme without payment of the premium. Moreover, minors below five years are prone to diseases. In the Ghanaian context, the physical environment is sometimes disease prone. Most of these people who suffer from diseases are minors who could put some financial strain on the scheme.

Table 4. Marital status of subscribers

\begin{tabular}{lc}
\hline Marital status & Percentage \\
Single & 38 \\
Married & 55 \\
Divorced & 5 \\
Widowed & 2 \\
Total & 100 \\
\hline
\end{tabular}

Source: Authors

field work 2015

\section{Educational level of scheme managers and subscribers}

All five managers had been educated to the tertiary level. Additionally, it was only the scheme manager who has a Post Graduate Certificate in Public Administration. Thus, apart from the Public Relations Officer who has a diploma, all the rest had at least a bachelor's degree from different fields of endeavor. The study showed that the educational level for the majority of subscribers who took part in the study was quite low. This low educational background of the subscribers which reflected the general educational level of the people in the district was not seen as healthy for national development. A good number, twenty two percent $(22 \%)$ of the subscribers, who took part in the study, indicated that they had no formal education. More than half, representing seventy percent $(70 \%)$ of the subscribers who responded to the questionnaire had not been educated beyond secondary level (Table 5).

Table 5. Educational background of subscribers

Level Percentage




\begin{tabular}{lc}
\hline No formal education. & 22 \\
Basic education & 28 \\
MLSC & 8 \\
Secondary & 15 \\
Tertiary & 25 \\
Others & 2 \\
Total & 100 \\
\hline
\end{tabular}

Source: Authors Fieldwork, 2015

From the table above, only thirty percent (30\%) of respondents were educated beyond the secondary level. It is believed that people with little or no education are more likely to fall sick than those who are well educated. This is because those who are well educated are more conscious of their health and may pay more attention to preventive health care than the less educated. This implies that the scheme may pay high bill on the account of the majority who have little or no education.

\subsection{Occupational background of Respondents}

Table 6. Occupation of Subscribers

\begin{tabular}{lc}
\hline Occupation & Percentage \\
\hline Student & 15 \\
Unemployed & 7 \\
Farming & 18 \\
Trading & 24 \\
Civil/Public service & 14 \\
Self-employed & 9 \\
Pensioner & 5 \\
Driver & 2 \\
Teachers & 3 \\
Others & 3 \\
Total & 100 \\
\hline
\end{tabular}

Source: Author's Field work, 2015

With the exception of the subscribers, the other two categories of respondents (the scheme managers and the service providers) had similar background and related job experiences. The scheme management works with the scheme while the service providers' work in a health or health related facility. Unlike the scheme managers and the providers, the subscribers to the scheme indicated a wide range of jobs. The occupational backgrounds indicated by the respondents vary. They included: driving, pensioners, students, assembly members, private business, civil servants, teaching and farming.

It was found that the three most common occupations among the subscribers were trading or private business representing thirty-three percent $(33 \%)$ followed by farming, eighteen percent $(18 \%)$ and then civil/public servants fourteen percent $(14 \%)$ as shown in table six. Farming and trading constituted forty-two percent $(42 \%)$ of the respondents as compared to the civil /public servants who formed only fourteen percent (14\%), while the unemployed accounted for seven percent $(7 \%)$ of the subscribers. It could be said that this finding reflected the low educational background of the subscribers in the municipality. As a result, few people were noted to be working in the civil/ public sector, which invariably require higher educational qualification.

\subsection{Perceptions and opinions on the accessibility of the scheme}

The study showed that the health insurance scheme in the Ejisu-Juaben Municipality is performing well. Opinions about the accessibility of the health insurance scheme did not differ greatly among scheme managers, service providers and the subscribers. The dominant view expressed was that the scheme has made health care affordable and accessible in the municipality. When respondents were asked to rate the performance of the scheme on a four point likert scale, forty percent $(40 \%)$ representing two of the management team members rated the performance as good, while the rest representing sixty percent (60\%) (Frequency) rated the performance of the scheme as very good. The study confirmed that in recent times, the scheme has witnessed some significant increase in the number of subscribers. Subsequently, many subscribers have benefited from affordable and accessible health care. For instance, by the end of 2008, two thousand and thirty-six (2036) people had subscribed to the scheme, a number which increased by five percent (5\%) to 
three thousand two hundred and thirty-eight (3238) by the end of 2009 (EJMHIS Annual Report, 2009). This was evident in the responses of the research participants; the scheme managers and service providers as well as the subscribers. They indicated that there had been an increase in subscriber membership in the municipality.

The study showed that health providers think that the performance is good. None of the providers rated the performance of the scheme as poor or unsatisfactory. Thus, thirty percent (30\%) and seventy percent (70\%) of the providers rated the performance "very good" and "good", respectively. Almost all the respondents mentioned that there had been increased access to health care. Moreover, the affordability of health care especially to the rural poor was another reason for rating the performance of the scheme as very good. The point of view of subscribers was not very different from that of the providers and the managers in their perception of the performance of the scheme. Subscribers were of the opinion that the scheme was performing very well in terms of accessibility, affordability and reliability. It was found that none of the subscribers rated the performance of the scheme as poor (Table 7). It could be said from the responses that both male and female respondents have good perception about the performance of the scheme. It is possible that they would maintain their membership with the scheme and ensure its sustainability.

Table 7. Subscribers' perceptions on the performance of the scheme by gender

\begin{tabular}{lccccccc}
\hline Performance & Male & & & Female & \multicolumn{2}{c}{ Total } \\
& Freq & $\%$ & Freq & $\%$ & Freq & $\%$ \\
\hline Excellent & 4 & 9.1 & 6 & 10.7 & 69.6 & 60 & 10 \\
Very good & 21 & 47.7 & 39 & 14.3 & 20 & 60 \\
Good & 12 & 27.3 & 8 & 5.4 & 10 & 10 \\
Fairly good & 7 & 15.9 & 3 & 100 & 100 & 100 \\
Total & 44 & 100 & 56 & & \\
\hline
\end{tabular}

Source: Authors Fieldwork, 2015

However, some of the subscribers expressed misgivings about corrupt practices by some staff of the scheme. They were of the view that these fraudulent acts were a threat to the sustainability of the scheme. They explained that money was collected without issuing receipts as directed. This was confirmed by the managers of the scheme who explained that there had been a number of cases where some card bearers could not access health care because their data was not captured by the scheme. This suggests that such cards had been illegally issued out.

\section{Challenges affecting the sustainability of the scheme}

The scheme is beset with a number of challenges. The following were some of the nagging challenges that were mentioned during the interview with the management team. The most dominant challenges included, ineffective claims by management and control, lack of effective mechanism for tracking claims, inconsistent billing system, undue delay of payment of claims due to providers. Again, Low billing rate introduced by the scheme is a great disincentive to the provision of quality health service delivery to those who actually need their services.

Another serious challenge mentioned was the abuse of the system by subscribers. It was revealed from the study that the scheme has been unnecessarily abused. They abused the system apparently because they think they have paid (irrespective of the amount paid) and would like to maximize their benefit at all cost even if there is no need to use a facility. This finding is central to the traditional concept of solidarity and risk sharing in African communities, the theoretical framework, upon which the research was based. With this concept of solidarity, a number of relationships and groupings existed, in which the members rely on each other's solidarity or even pool risks among a larger group. People came together when members were in financial difficulties, and for social and economic purposes. This contributed to the creation and reinforcement of social networks. Notably, this system was devoid of cheating since in the traditional rural societies when individuals made contributions, they expected a return only when the need arose. The informal risk-pooling arrangements were commonly based on balanced reciprocity, which is the standard for fairness (Huber, Hohmann \& Reinhard 2002). The scheme manager complained that subscribers moved from one health facility to another with the same sickness without completing treatment with the first facility visited. Moreover, multiple diagnoses of a particular sickness by some providers leading to a situation termed as "poly-pharmacy" and thereby increasing cost of health service delivery. This was seen by the scheme managers as threatening the sustainability of the health insurance scheme in the municipality. Other challenges mentioned by the scheme managers that affect the effectiveness and efficiency of the scheme included the following: lack of accommodation for staff, inadequate logistical support for running the office, unattractive remuneration and incentive packages for staff.

Even though the core management team for the scheme had lamented over a litany of challenges, they shared a positive attitude towards their job. It was important to note that all of the scheme management staff indicated that they enjoyed working with the scheme. As a matter of fact, all the five core staff of the scheme responded in the affirmative when 
asked whether they enjoyed working with the Health Insurance Scheme in the area. They indicated that they enjoyed working with the Ejisu-Juaben Health Insurance Scheme for various reasons. The reasons assigned was that they had been working to promote a good cause - implementing a good health policy, job satisfaction in working with the scheme, serving the needs of subscribers and working to enhance access to quality health care.

Another disturbing issue was related to the operational Information Communication Technology (ICT) platform introduced in 2008 to improve the flow of information from the local level to the national level by the health insurance authority. This concept was excellent but the Authority acquired a low speed broadband which was incapable of transmitting information sent by all the schemes to the national level. The platform was used to transmit both claims entries and data entry to the national level. The resultant effect of this was that it had slowed down operations and correspondence between the districts and the national head office. Difficulty in sending such data had led to the inability of the schemes to fulfill their promise of getting any person who pays the premium with a card within three months. This challenge is further exacerbated since the cards are produced at the Headquarters in Accra. For a card to be ready and its readiness for use was dependent on when the transmitted information got to Accra. Owing to the low speed of the broadband, there was backlog of client data at all the scheme levels.

\subsection{Challenges facing Healthcare Providers}

When the service providers were asked about the challenges that affect their operations, they mentioned undue delay of payment of claims, exclusion of some drugs from approved list and low tariff. The dominant problem mentioned by the providers was the delay in the payment of claims by the scheme. Almost all ninety five percent $(95 \%)$ of the service providers mentioned this as the major problem they face. The remaining five percent $(5 \%)$ stated undue delay of payment of claims as the second or the third major problem affecting their operations. Consequently, the service providers mentioned that these challenges affected the quality of service delivery in the municipality. They explained that the system of limiting providers to certain prescribed medicines has not been helpful. This is because there are people for whom the alternative drugs may simply not work for them due to certain peculiar conditions. They also expressed the view that the Health Insurance, notwithstanding its numerous benefits, was facing management crisis for non-payment of claims submitted to the National Secretariat of the Scheme. There have been complaints from health care providers about non-payment of outstanding claims for about six months. Meanwhile, the authority at the national level gives the local scheme a specific amount of money to manage for one quarter of the year. However, what is released does not meet even half of the claims submitted for the same period. The situation worsened in 2008 due to the increment in claims submitted by health care providers. This came about as a result of the authority changing from "itemized billing" to the current "diagnostic related grouping". It further worsened by the introduction of free delivery services to pregnant women. There is therefore a great difference between monies given to the schemes and claims submitted by service providers.

Table 8. Monthly payment schedule (2015)

\begin{tabular}{lcccc}
\hline Month & $\begin{array}{c}\text { Claims } \\
\text { Submitted Gh } \phi\end{array}$ & $\begin{array}{c}\text { Payment } \\
\text { Gh } \phi\end{array}$ & $\begin{array}{c}\text { Deductions } \\
\text { Gh } \phi\end{array}$ & $\begin{array}{c}\text { Indebtedness } \\
\text { Gh } \phi\end{array}$ \\
\hline JAN & $484,693.65$ & $473,231.56$ & $9,439.29$ & $2,022.80$ \\
FEB & $457,536.36$ & $448,021.99$ & $9,514.37$ & - \\
MAR & $545,474.49$ & $533,221.69$ & $8,303.14$ & $3,949.66$ \\
APR & $548,495.93$ & $538,752.22$ & $5,469.88$ & $4,273.83$ \\
MAY & $577,519.34$ & $561,496.26$ & $9,903.30$ & $6,119.78$ \\
JUN & $658,937.56$ & $626,620.00$ & $10,459.94$ & $21,857.62$ \\
JUL & $622,815.87$ & $586,352.74$ & $8,944.80$ & $27,518.33$ \\
AUG & $594,235.69$ & $72,678.50$ & - & $521,557.19$ \\
SEP & $489,530.88$ & $2,272.54$ & - & $487,258.34$ \\
OCT & $462,891.34$ & $2,031.56$ & - & $460,859.78$ \\
NOV & $331,134.66$ & - & - & $331,134.66$ \\
DEC & $549,045.18$ & - & - & $549,045.18$ \\
Total & $6,322,310.95$ & $3,844,679.06$ & $62,034.72$ & $2,415,597.17$ \\
\hline
\end{tabular}

Source: EJMMHIS Annual Report, 2015

Table 8 provides an overview of the indebtedness of the EJHIS in 2012. By the end of December the scheme was owing providers to the tune of two million, four hundred and fifteen thousand five hundred and ninety seven point one-seven Ghana cedis $(\mathrm{GH} \phi 2,415,597.17)$. Similarly, for a period of eleven months, the scheme was able to save an amount of sixty two thousand, three hundred and four point seven-two Ghana cedis ( $\mathrm{GH} \phi 62,034.72)$ which were deductions from claims submitted by service providers. This therefore reveals that submitted claims contained some errors. 
The findings of the study have been confirmed by a report in the Daily Graphic by Sodzi-Tettey, June 1, 2010 (Yeboah-Awudzi 2010). It was reported that the failure of mutual health insurance schemes in the Kumasi metropolis to pay claims to health service providers in their catchment area was seriously undermining quality health delivery. According to the Kumasi Metropolitan Director of Health Services, Dr. Kwasi Yeboah-Awudzi, mutual health insurance schemes in the metropolis had not paid claims to accredited hospitals and pharmacy shops since May 2009, making it difficult for the health service providers to generate the requisite revenue to replenish drugs and other medical supplies needed to enhance quality service delivery. It was said that the schemes owed about four million, five hundred and seventy four thousand, five hundred and seventy one Ghana cedis (GH 4,574,571) to some hospitals and clinics in the Kumasi metropolis and its environs. Thus, hospitals in Kumasi were running out of consumables and drugs and their managements were also being constantly harassed by those who supply them with medical consumables to run the hospitals (Sodzi-Tettey, June 1, 2010). Expressing concern on the situation, Dr. Yeboah-Awudzi said, in December 2009, medical superintendents in the metropolis complained bitterly about the undue delay in paying claims and appealed to the government to intervene as a matter of urgency. The foregoing discussion provides evidence that the scheme has not been able to comply with section 38(1) of the L.1 1809 whilst health care providers do honour section 37 (7) of L.1 1809. This raises concerns about the efficiency of the scheme. If the scheme owes some providers, then the obvious and unanswered question is whether the scheme is sustainable enough to serve the needs of subscribers. Apart from the non-payment of claims to service providers, the scheme also has not been paying claims regularly to accredited pharmacy shops. As a result, they also refuse to give the requisite drugs to members of the scheme who present prescriptions, thus undermining quality health care delivery. This therefore threatens the reason d'être of the establishment of the scheme to provide affordable and accessible quality health care delivery to all subscribers.

Additionally, the health insurance drug price list has not been reviewed since 2008. As a result of the non-review, there are a number of drugs on the health insurance list that is cheaper than the cost price in the market. This implied that supplying such drugs to clients would be at a loss to the providers. According to the Ghana Medical Association (GMA), as a result of non-payment of claims, most health care facilities owe substantial amounts of money in medicines and consumables procured on credit. Due to the indebtedness, suppliers were no longer willing to supply on credit. In its statement, the GMA said the Korle-Bu Teaching Hospital was owed (GH2.7m) two point seven million Ghana cedi, the Central Regional Hospital - six hundred and ninety four thousand Ghana cedi (GH $\not$ 694,000), the Eastern Regional Hospital one million and ninety thousand Ghana cedi $(\mathrm{GH} \not 1,090,000)$ with similar example elsewhere. This situation, the association stated had enormously affected the ability of those facilities to provide quality service to their clients including shortage of drugs and other essential supplies (Sodzi-Tettey 2010).

\subsection{Challenges Facing Subscribers}

A number of problems were enumerated by the subscribers as affecting access to quality health care. Dominant among the problems were: delays at health facilities due to increased attendance; inadequate equipment and personnel as well as long distance to facilities (Table 9). As many as 33\% of the subscribers complained that there have been frequent prescriptions of drugs and quite often, expensive drugs which the scheme did not cover.

Table 9. Problems with Card Bearers

\begin{tabular}{ll}
\hline Response & Percentage \\
\hline Unfriendly practitioners & 3 \\
Prescription of medicine outside the drug list & 33 \\
Delay due to increased attendance & 15 \\
Inadequate equipment and personnel & 10 \\
No problem & 12 \\
Unauthorized money collection & 5 \\
Long distances to facilities & 20 \\
Total & 100 \\
\hline
\end{tabular}

Source: Author's Fieldwork, 2015 
The prescription of drugs outside the price list was a worrisome phenomenon. Subscribers explained that card-bearers were denied or were not allowed to be administered certain kinds of drugs irrespective of the disease or needs of the patient. The study confirmed service providers' assertion that this policy did not promote quality health delivery in the municipality. From Table 9, fifteen percent (15\%) of the subscribers mentioned delay at health facilities as one of the major challenges they encounter as recipients of health care. The respondents attributed the apparent increasing number of people accessing health care in the district to the introduction of the Municipal Health Insurance Scheme (MHIS). The table also shows that a form of unauthorized money is been collected by some health personnel, especially in public health facilities. At least five percent of the subscribers stated this as a practice which stifles the principle of providing affordable and accessible health care.

\subsection{Role of Service Providers in Providing Quality Health Care}

Service providers play a critical role in ensuring the provision of quality health care. Quality health delivery depends on the good will and cooperation of all stakeholders such as the government, the scheme, the providers and the subscribers.

The study confirmed the fact that health providers have a critical role to play in ensuring quality health delivery in the Ejisu-Juaben Municipality. Measured on a four point Likert scale, three (3) out of five (5) representing sixty percent $(60 \%)$ of the scheme managers, "strongly agreed" to the key role of health providers. Similarly, seventy percent (70\%) of the subscribers who participated in the study indicated that they "strongly agree" to the statement, while the remaining thirty percent $(30 \%)$ of the respondents "agreed." This implied that none of the respondents disagreed with the fact that providers play critical role in providing quality health care in the district. This underlines the fact that the subscribers, irrespective of their sexes, appreciate the fact that the quality health care they enjoy is largely dependent on the health providers who work in collaboration with other stakeholders. It also implies that both male and female in the municipality have confidence in the scheme, hence their increasing patronage.

On the question of how providers served card bearers, respondents were unanimous that their services are good. This means that they had done their best in the circumstances to serve card bearers in spite of the constraints that they faced. It emerged from the study that "card bearers" and "non-card bearers" more often than not are treated differently. In the estimation of the members of the scheme management, some doctors, nurses and other health providers react to card bearers and non-card bearers differently. Reasons given for the apparent discrimination in reaction were as follows:

Since non-card bearers pay cash instantly, health providers feel at home and very much at ease with that. Non-card bearers and the use of cash and carry promote swift and efficient service delivery. The scheme has placed some limitation on the type of drugs that can be prescribed for card bearers; this is discriminatory. However, the providers stated that the effectiveness of their role is to a large extent dependent on how well the nagging challenges that confront the scheme were addressed. Service providers outlined a number of factors that may enhance their role in the scheme. Prominent among them were: regular and full payment of claims, cooperation from other stakeholders, education and free flow of information.

The study found out that service providers are capable of cheating the system through omission and commission that may affect the sustainability of the health insurance scheme. When the scheme managers were asked in what ways they think service providers can cheat the system, they mentioned the following as dominant: writing of multiple diagnoses leading to prescription of many drugs, inflating the attendance list, substituting less expensive drugs with expensive ones on the claims forms and inflating drug quantity, among others.

\subsection{Access to and use of Health Facilities}

Almost all respondents (97 percent) had access to a health facility in their own town or village, and 91 percent had access to a facility within $3 \mathrm{~km}$ of their home. For most people ( 89 percent), however, the nearest facility was a chemist or pharmacist. Fifty-eight percent had access to herbalist and (57) fifty seven per cent to a government clinic. Only one quarter had access to a government hospital, and about (20) twenty percent had access to a private clinic and (19) nineteen percent to a mission hospital.

Table ten presents an overview of the most common diseases reported at the health facilities for medical attention. For 2014, malaria accounted for almost (60) sixty percent of the ten top diseases that were reported to the facilities. It stands to reason, therefore, that if the preventable diseases such as malaria, diarrhea and typhoid fever are reduced through education and good health practices, bills submitted to the scheme would also be reduced.

Table 10: Top ten causes of OPD attendance (2014 and 2015)

\begin{tabular}{lllllc}
\hline & 2014 & & 2015 & \\
Diseases & Cases & $\%$ & Diseases & Cases & 59.9 \\
\hline Malaria & 85,855 & 40.3 & Malaria & 127,101 & 5 \\
\hline
\end{tabular}




\begin{tabular}{|c|c|c|c|c|c|}
\hline Acute respiratory infections & 17,517 & 8.2 & $\begin{array}{l}\text { Acute respiratory } \\
\text { infections }\end{array}$ & 22,837 & 10.6 \\
\hline $\begin{array}{l}\text { Rheumatism and } \\
\text { joint pains }\end{array}$ & 9,111 & 4.3 & $\begin{array}{l}\text { Rheumatism and } \\
\text { joint pains }\end{array}$ & 12,143 & 5.7 \\
\hline $\begin{array}{l}\text { Skin diseases and } \\
\text { ulcers }\end{array}$ & 8,072 & 3.8 & $\begin{array}{l}\text { Skin diseases } \\
\text { and ulcers }\end{array}$ & 11,985 & 5.6 \\
\hline Diarrhoea & 7,179 & 3.4 & Diarrhoea & 10,381 & 4.9 \\
\hline Hypertension & 6,781 & 3.2 & Hypertension & 9,096 & 4.3 \\
\hline $\begin{array}{l}\text { Pregnancy and } \\
\text { related }\end{array}$ & 4,618 & 2.2 & Acute eye infection & 7,581 & 3.6 \\
\hline Acute eye infection & 4,501 & 2.1 & Vaginal discharge & 4,346 & 2 \\
\hline Chicken pox & 3,630 & 1.7 & Typhoid/enteric fever & 3,472 & 1.7 \\
\hline Dental caries & 3,545 & 1.6 & Intestinal worms & 3,378 & 1.5 \\
\hline Sub total & 150,809 & 70.9 & Sub-total & 212,320 & 75.3 \\
\hline All others & 61,759 & 29.1 & All others & 69,660 & 24.7 \\
\hline Grand total & 212,568 & 100 & Grand total & 281,980 & 100 \\
\hline
\end{tabular}

Source: Ejisu-Juaben Health Directorate (EJHD), 2015

A cursory look at Table 10 shows an increase in the number of attendances to the 'out-patient-department' (OPD) in 2009. This confirms the fact that access to health care in the district has increased.

\section{Accessibility of Scheme to Subscribers}

It was evident from the responses given by the management team that the scheme has improved access to quality health care in the Ejisu-Juaben. With the card in hand, people who previously could not visit any health facility can now receive that service. Moreover, they mentioned that subscribers are more frequently and more often using health facilities now than before. They substantiated their claim by mentioning that there has been significant increase in the number of patients who use the health facilities in the district in recent times. Accordingly, the service providers mentioned "card-bearers" as now forming the majority of their clients.

Table 11. Hospital attendance in the Ejisu-Juaben from 2007 to 2015

\begin{tabular}{ll}
\hline Year & Hospital attendance \\
\hline 2007 & 77,377 \\
2008 & 122,933 \\
2009 & 131,508 \\
2010 & 174,202 \\
2011 & 195,970 \\
2012 & 219,950 \\
2013 & 242,406 \\
2014 & 337,685 \\
2015 & 415,048 \\
\hline
\end{tabular}

Source: Ejisu-JuabenHealth Directorate (EJMHD), 2015

It was thus, evident from the study that since the inception of the mutual health insurance scheme in the district, attendance to health facilities has been increasing and subscribers to the scheme form the bulk of the people who access health care in the district (Table 11). It could be deduced from this that the health insurance scheme is capable of promoting access to quality health care in the district. Furthermore, when the scheme managers were asked whether in their estimation, the premium paid by subscribers was affordable, they all responded in the affirmative. To them the premium paid by subscribers was moderate and very affordable. Perhaps they were informed by the increasing number of subscribers joining the scheme on daily basis. On the other hand, the subscribers shared divergent views on the affordability of the scheme. According to the responses, sixty five percent (65\%) of the subscribers indicated that the premium paid is very affordable. However, the remaining thirty five percent $(35 \%)$ indicated that the premium is not affordable and that they expected it to be free. The results show that those who thought the premium was expensive were made up of petty traders, farmers and the unemployed.

\section{Conclusion}

Mutual health insurance scheme is now being considered as a key to providing affordable and accessible quality healthcare for the majority of Ghanaians. The scheme has made healthcare accessible and affordable to both rich and the poor in both urban and rural communities. People who hitherto could not access health facilities can now receive medical attention early enough to avoid complications. In practice, health insurance scheme covers out-patient and inpatient cases, including accidents and investigations. Also this research reveals specific problems such as fraudulent claims, undue delay in the payment of claims submitted for refund, delay in accessing healthcare due to increasing 
number of attendance to health facilities. The others include limited and inadequate logistics, equipment and personnel to ensure effective management of the scheme and also the question of accredited health providers in the district.

It is therefore essential to ensure effective collaboration between the scheme management and the accredited service providers so that subscribers will enjoy quality and accessible healthcare. Subscribers should also desist from moving from one health facility to the other with the same sickness without completing at the first facility. To ensure sustainability, subscribers should visit health facilities when they are sick or going for a medical review.

\section{References}

Adoma-Yeboah, L. (2005, September 14). Financing Health Care in Ghana since Independence, Daily Graphic

Asenso-Okyere, W. K., Anum, A., Osei-Akoto, I., \& Adukonu, A. (1998). Cost recovery in Ghana: Are there any changes in health care seeking behavior, Health policy and planning, 13(2), 63-94, http://dx.doi.org/10.1093/heapol/13.2.181

Asenso-Okyere, W. K., Osei-Akoto, I. Anum, A., \& Appiah, E. N. (1997). Willingness to pay for health insurance in a developing economy, A pilot study of the informal sector of Ghana using contingent valuation. Health policy, 42, 223-237. http://dx.doi.org/10.1016/S0168-8510 (97)00069-9

Asenso-Okyere, W. K., Osei-Akoto, I., Anum A., \& Adukonu A. (1999). The behaviour of health workers in an Era of Cost Sharing: A Study of Ghana's Cash and Carry System, Tropical Medicine and International Health, 4(8), 142-175. http://dx.doi.org/10.1046/j.1365-3156.1999.00438.x

Best, J. W., \& Kahn, J. V. (1995). Research in education, 7th Ed. New Delhi: Prence-Hall.

Cooper, D. R., \& Schindler, P. S. (2001). Business research methods, 7th Ed. New York: McGraw-Hill/Irwin.

Criel, B. (1998). District-based health insurance in Sub-Saharan Africa, Part 1: From theory to Practice, Studies in health services organisation and policy 9, Antwerp, Belgium.

Daily, G. (2008, July 9). British Government support free maternal care in Ghana, Daily Graphic.

Ghana Statistical Service, (2003). Ghana living standards survey, report of the fourth round (GLSS4), Ghana Statistical Service Accra,

Ghana Statistical Service, (2003). Poverty trends in Ghana in the 1990s, Ghana Statistical Service, Accra,

Ghanaweb.com. Health Insurance in Ghana, Accessed on September 24, http://www.ghanaweb.com/GhanaHomePage/health/national- health-insurance-scheme.php.

Glesne, C. (2005). Becoming qualitative researchers: An introduction, Boston, MA: Person

Glesne, C., \& Peskin, (1992). Becoming qualitative researchers: An introduction. White Plains, NY: Longman.

Goodman, H., \& Waddington, C. (1994). Financing health Care, UK: Oxfam Press, 1994

Huber, G., Hohmann, J., \& Reinhard, K. (2002). Mutual health insurance (MHO) five years' experience in West Africa; concerns, controversies and proposed solutions, Bonn: GTZ

Kashner, T. M., Muller, A., Richter, E., Hendricks, A., \& Ray, D. (1998),private health insurance and veterans us of veterans affairs care. Rate project committee, Rate alternative technical evaluation" Med Care, 36(7), 1085-9

Ministry of Health, (1999), Sector 5-Year Programme of Work (1997- 2001): 1998 Review. Ministry of Health, Accra

Ministry of Health, (2003), Annual Report, Accra

Modernghana.com. (2014, September 24) Health Insurance Scheme in Ghana, Accessed on September 24, 2014, 5:07pm, from http://www. modernghana.com/219867/1/nhis- seized-byndc.html

National Health Insurance Scheme (2004) National Health Insurance Policy Framework for Ghana: NHIS, Accra

Osei-Akoto, I. (2004). Demand for voluntary health insurance by the poor in developing countries: Evidence from rural Ghana. Centre for Development Research, Bonn, Germany

Osei-Akoto, I., Oduro, A., \& Acquaye, I. (2002) Poverty in a globalizing economy: The role of rural institutions, Ghana. Africa-Asia research report, Capacity Building Network for African Development Project, Nairobi: African Development Centre, 2002

Osuala, E. C. (1993). Introduction to research methodology. Onistsha: African Publishers Ltd.

Personal Communication (2015), Interview with Mr. Enoch Kwarteng, at his office, Ejisu $20^{\text {th }}$ January, 2015

Platteau, J. P. (1997). Mutual Insurance as an Elusive Concept in Traditional Rural Communities, Journal of 
Development Studies, 6(33), 764-796. http://dx.doi.org/10.1080/00220389708422495

Saltman, R. B., \& Dubois, H. F. W., Current reform proposals in social health insurance countries, Eurohealth, 11(1), $10-14$

Saltman, R. B., \& Dubois, H. F. W. (2004). Individual incentive schemes in social health insurance systems. Eurohealth, 10(2), 21-25

Saltman, R. B., Busse, R., \& Figueras, J. (2004) Social health insurance systems in Western Europe. Berkshire/New York: Open University Press

Sarantakos, S. (1998) Social Research, 2nd ed. London: Macmillan Press Ltd, 1998

Sodzi-Tettey, S. (2010) Save the NHIS. Daily Graphic

Wassa West District Health Directorate Annual Report, Ministry of Health: Accra, 2008

Wassa West District Health Directorate, Annual Report, Ministry of Health: Accra, 2009

Wassa West Health Insurance, Annual Report Accra: National Health Insurance Authority, Accra, 2009

Wassa West Health Insurance, Annual Report. Accra: National Health Insurance Authority, Accra, 2008

World Health Organization (2008) Health systems: Improving performance, The World Health Organization, Geneva

\section{(cc) Br}

This work is licensed under a Creative Commons Attribution 3.0 License. 